\title{
A closer look at travellers' infections abroad : Finnish nationwide data with incidences, 2010 to 2012
}

\section{Siikamäki, Heli}

2017

Siikamäki , H , Kivela , P , Fotopoulos , M \& Kantele , A 2017 , ' A closer look at travellers' infections abroad : Finnish nationwide data with incidences, 2010 to 2012 ' , Travel medicine and infectious disease, vol. 15 , pp. 29-36 . https://doi.org/10.1016/j.tmaid.2016.10.007

http://hdl.handle.net/10138/236604

https://doi.org/10.1016/j.tmaid.2016.10.007

publishedVersion

Downloaded from Helda, University of Helsinki institutional repository.

This is an electronic reprint of the original article.

This reprint may differ from the original in pagination and typographic detail.

Please cite the original version. 


\title{
A closer look at travellers' infections abroad: Finnish nationwide data with incidences, 2010 to 2012
}

\author{
Heli Siikamäki a, b, Pia Kivelä a , Mikael Fotopoulos ${ }^{\text {b }}$, Anu Kantele a, c, * \\ ${ }^{a}$ Inflammation Center, Division of Infectious Diseases, University of Helsinki and Helsinki University Hospital, POB 348, FI-00029 HUS, Helsinki, Finland \\ b SOS International, Nitivej 6, DK-2000, Frederiksberg, Denmark \\ ${ }^{\text {c } K a r o l i n s k a ~ I n s t i t u t e, ~ D e p a r t m e n t ~ o f ~ M e d i c i n e / S o l n a, ~ U n i t ~ o f ~ I n f e c t i o u s ~ D i s e a s e s, ~ S E ~} 17176$ Stockholm, Sweden
}

\section{A R T I C L E I N F O}

\section{Article history:}

Received 1 September 2016

Received in revised form 8 October 2016

Accepted 18 October 2016

Available online 21 October 2016

\section{Keywords:}

Travel

Incidence

Morbidity

Infection

Traveller's diarrhoea

Respiratory infection

Vaccine-preventable

\begin{abstract}
A B S T R A C T
Background: Although infections represent the most common health problem of travellers abroad, data on morbidity and incidences of various infections are scarce.

Method: Data on infections of Finnish travellers during 2010-2012 were retrieved from the database of SOS International, an assistance organization covering 95\% of Finns requiring aid abroad. The study included 30,086 cases. For incidence calculation, the data were linked to the numbers of Finns visiting these regions during the same period as recorded by the Official Statistics of Finland.

Results: The incidence of infections was particularly high in Africa, southern Europe plus the eastern Mediterranean, and Asia plus Oceania. The most frequent diagnoses were acute gastroenteritis (38.0\%) and respiratory-tract infections (RTI) (34.5\%), followed by infections of the ear (12.6\%), skin or subcutaneous tissue (5.1\%), urogenital tract (4.2\%), eye (3.1\%), and systemic febrile infections (2.2\%). Vaccinepreventable diseases (VPD) accounted for $0.8 \%$ of cases, with varicella as most (49\%) and influenza as second-most (27\%) common.

Conclusions: Incidence of infections was higher in southern than in eastern and western Europe. Gastroenteritis and RTI proved the most frequent diagnoses, whereas systemic febrile infections were uncommon. Despite pre-travel immunizations, VPDs still occurred; pre-travel consultation should cover both varicella and influenza.
\end{abstract}

๑) 2016 Elsevier Ltd. All rights reserved.

\section{Introduction}

International travel has, in recent decades, increased substantially; annual international tourist arrivals are expected by 2030 to reach 1.8 billion, with travel to emerging economies increasing at twice the pace of travel to advanced regions [1]. Accordingly, travellers are anticipated to cause a rising burden on health care systems both in the regions visited and in their home countries after return. Over half the visitors to developing countries have been reported to fall ill, and $8 \%$ to require medical attention [2]. Less

Abbreviations: OSF, the Official Statistics of Finland; RTI, respiratory-tract infections; SOS, SOS International; TD, travellers' diarrhoea; VPD, vaccinepreventable disease.

* Corresponding author. Inflammation Center, Division of Infectious Diseases, University of Helsinki and Helsinki University Hospital, POB 348, FI-00029 HUS Helsinki, Finland.

E-mail addresses: heli.siikamaki@hus.fi (H. Siikamäki), pia.kivela@hus.fi (P. Kivelä), mfo@sos.eu (M. Fotopoulos), anu.kantele@hus.fi (A. Kantele). data are available on travel to developed countries. Recently, we showed that more than half of all health problems during travel are infections [3].

Most studies present the proportionate morbidity of returning travellers, often reporting data from centres specialized in travel and tropical medicine [4-15]. As for health problems while abroad, data have been collected mainly after travellers' return [2,16-20], with figures recorded during the actual journeys being scarce [21-23]. Until recently, reports on incidences, meaning cases related to numbers of travellers to each region, have been lacking [24].

The largest group among all international travellers are the Europeans. Even though they represent only $10 \%$ of the world population, they are responsible for half of world's international arrivals [1]. Our earlier report [3] presented data on 50,710 Finnish travellers with health problems abroad, as retrieved from an assistance organization (SOS International) covering 95\% of Finns requiring aid abroad. In addition to presenting proportionate morbidity, we combined those data with the annual numbers of 
travellers to various destinations that are recorded in the Official Statistics of Finland (OSF) [25], enabling calculation of incidence of illness and injury during travel. The study not only found significant differences in incidences between geographic regions, but also demonstrated that infections (60\%) outnumber all other health problems. We now revisit these data to study the incidences of infections in various geographic regions and to examine their types in more detail.

\section{Methods}

\subsection{Assistance organization data}

SOS International (SOS), serving Nordic and Baltic insurance companies, provides travellers with 24-h emergency assistance: advice, medical evaluation, referral to treatment, cost coverage and arrangement of transportation if indicated for medical reasons. SOS covers approximately 95\% of all Finnish cases (77\% of inpatients, 99.8\% of outpatients) handled by assistance organizations of insurance companies abroad [3]. The study material covers Finnish travellers that used health care services abroad and were reported to SOS. Coordinating doctors are assigned to $86 \%$ of inpatient and $1 \%$ of outpatient cases [3]. They stay in contact with patient and clinician abroad, examine medical reports, evaluate treatment, and give orders for repatriation. Non-medical assistance coordinators see to the uncomplicated inpatient, and to $99 \%$ of outpatient cases, recording diagnoses provided by clinicians abroad [3]. Earlier, we retrieved data on all cases, 1 January 2010 to 31 December 2012, a total of 50,710 . For the present study we selected only those cases diagnosed with infection (Fig. 1).

All SOS data are processed in a computerized database and comprised information on age, sex, time and country of illness, inpatient or outpatient status, main diagnosis, repatriation, and death. Research permission came from SOS.

\subsection{OSF data}

The OSF data on Finnish travellers comprise annual numbers and median duration of at-least-overnight leisure, business and professional visits abroad, and travellers' age groups by region and country. The initial data collection included monthly sample-based computer-assisted telephone interviews with Finnish residents aged 15-74 years; in 2012, the upper age limit was extended to 84 years. The samples, systematically drawn from the central population register, totalled 26,400 individuals annually in 2010 and 2011, and 28,200 in 2012 [25].

\subsection{Definitions}

A case was defined as a Finnish traveller abroad with one episode of illness that received a diagnosis of infection, a case handled by SOS during 2010-2012. Anyone with several separate episodes was thus counted more than once. Repatriations were grouped based on manner of return: as planned, by air ambulance, or by other rearranged transport.

\subsection{Diagnoses}

Coordinating doctors had encoded the diagnoses, applying the International Statistical Classification of Diseases and Related Health Problems 10th revision (ICD-10) [26]. Assistance coordinators had recorded them as open text. For the present study, a single coordinating doctor, one of the researchers (HS), encoded these diagnoses applying ICD-10. We separated infection diagnoses from the ICD-10 organ-specific classification into a category of their own and classified them further under the following subcategories: acute gastroenteritis, respiratory tract infections, infections of the ear, infections of the skin or subcutaneous tissue (dermatologic infections), infections of the urogenital tract, infections of the eye, systemic febrile infections, and other infections.

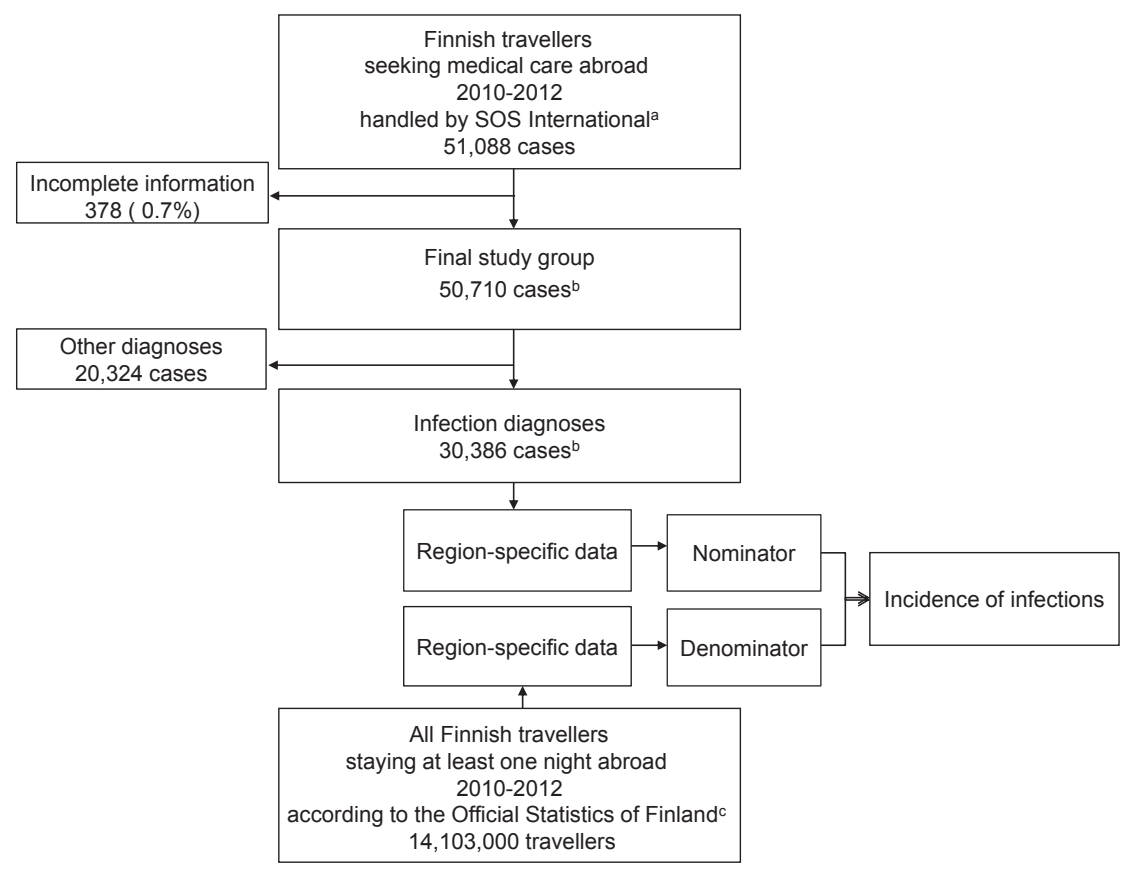

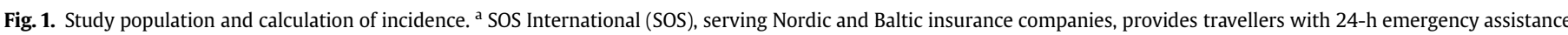

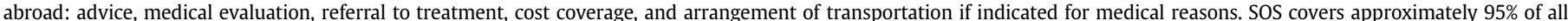

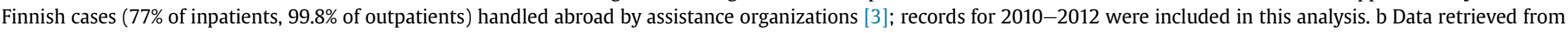
[3]. c Overnight leisure and business trips abroad; includes travellers 15-74 years of age in 2010-2011, and travellers 15-84 years of age in 2012 [25]. 


\subsection{Calculation of incidence}

Principles of incidence calculation are described in Fig. 1 and appear in more detail in Supplementary Table 1 and our earlier report [3]. For compatibility with the OSF population, incidence calculation was restricted to adults. For incidence calculations, we modified the geographic classification to make it compatible with the OSF classification [25]. No incidences appear for the Nordic or Baltic countries or Russia, because proportionally more cases are covered by the Social Insurance Institution of Finland (Kela), and visits are shorter than elsewhere, thus hampering comparison with other regions [3].

\subsection{Statistical methods}

Details of statistical analysis of the incidences and estimation of the 95\% Bayesian credible intervals (BCI) are described in Supplementary Table 1 and our earlier report [3]. Analysis of descriptive statistics was with Microsoft Excel 2010 and IBM SPSS 19.0. Differences between groups were tested with chi-squared and Student's t-tests and the Kruskal-Wallis test, as appropriate.

\section{Results}

The analysis included 30,086 cases; median age was 40 years [interquartile range (IQR) 15-59]; 55.7\% were women. Most cases $(20,264)$ were reported in southern Europe plus the eastern Mediterranean (Table 1).

Table 1

Characteristics of cases $^{\mathrm{a}}$ abroad with infection diagnosis, 2010-2012.

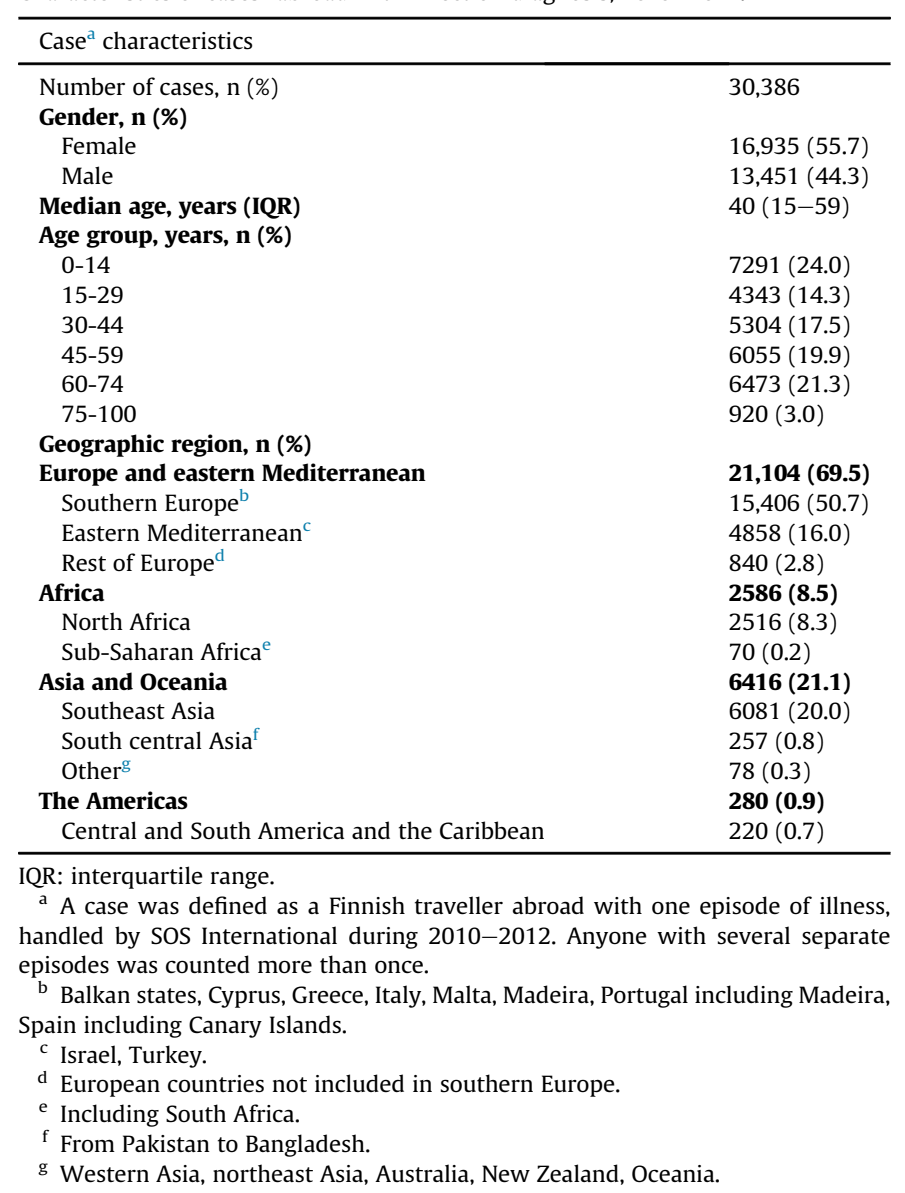

\subsection{Incidence of infections - general outlines}

Infection incidence was greatest in Africa, in southern Europe plus the eastern Mediterranean, and in Asia plus Oceania. Incidence was low in the Americas and in eastern plus western Europe (Table 2).

Acute gastroenteritis was most common in Africa, respiratorytract infections (RTI) in southern Europe and the eastern Mediterranean. Ear, dermatologic, and urogenital infections were most commonly reported from southern Europe plus the eastern Mediterranean or Asia and Oceania. Incidences of urogenital and eye infections were highest in southern Europe plus the eastern Mediterranean.

\subsection{Proportionate morbidity - overview}

Acute gastroenteritis (11,544 cases) proved to be the most common diagnosis (38\%), followed by respiratory tract infections (35\%), infections of the ear (13\%), skin or subcutaneous tissue (5\%), urogenital tract (4\%), eye (3\%), systemic febrile infections (2\%), and other infections $(0.2 \%)$ (Table 3$)$.

Of all cases, $87 \%$ were treated as outpatients and $13 \%$ as inpatients (Table 4 ); $12 \%$ of women and $15 \%$ of men were hospitalized ( $p<0.05)$. The most common reason for hospital treatment was acute gastroenteritis (66\% of inpatients). Data on duration of hospital stay were incomplete; of the gastroenteritis cases, data were available for 730 cases with a median duration of 2 days (IQR $1-3$ ). Patients with gastroenteritis needed hospitalization more often (23.3\%) than did those with RTI $(7.1 \%)(\mathrm{p}<0.05)$.

Of the ear infection cases, $53 \%$ had otitis media, $59 \%$ of whom were under age 15 . Of the dermatologic infection cases, $80 \%$ were superficial infections of the skin and subcutaneous tissue. Of all cases with infection of the ear, skin, urogenital tract, or eye, most received treatment as outpatients.

Of all cases, $0.8 \%$ had a vaccine-preventable disease (VPD) with varicella as the most common, followed by influenza, herpes zoster, typhoid fever, and single cases of hepatitis A/B, measles and mumps. Of the varicella cases, $86 \%$ were children under age 15 .

\subsubsection{Age}

When compared to other age groups, the proportion of acute gastroenteritis was greatest in the age groups 15 to 29,30 to 44 , and $45-59$ years $(\mathrm{p}<0.05)$ (Fig. 2$)$, while that of RTI increased with age, being greatest for those aged 60 to 74 and $75-100$ years $(p<0.05)$. In children (0-14 years), the proportion of ear infections and systemic febrile infections was larger $(p<0.05)$, and that of dermatologic infections smaller $(p<0.05)$ than in other age groups.

\subsection{2. $\operatorname{Sex}$}

The proportion of acute gastroenteritis and ear infections was greater in men ( $p<0.05)$, whereas women had a higher proportion of respiratory, urogenital, and eye infections $(\mathrm{p}<0.05)$ (Table 5).

\subsubsection{Repatriation and deaths}

In $509(1.7 \%)$ cases, the return travel required re-arrangement (Table 6). Eight cases (0.03\%) needed transport by air ambulance. The data included four deaths: three cases of sepsis, including one melioidosis, and one pneumonia.

\section{Discussion}

Whereas numerous studies provide data on proportionate morbidity from a variety of diseases in travellers, this is - to the best of our knowledge - the first study to present, in a single report, the actual incidence figures of the various infections in travellers 


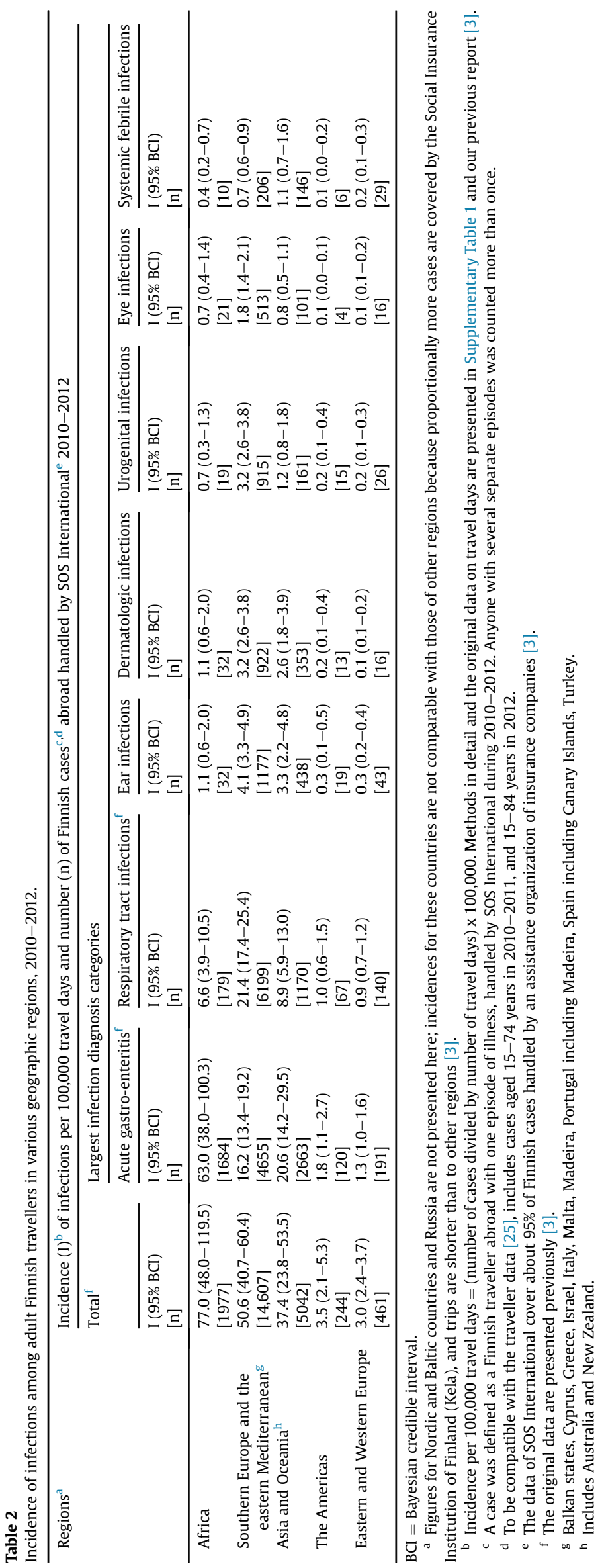

Table 3

Diagnoses of infection cases ${ }^{\mathrm{a}}$ among travellers abroad, 2010-2012.

\begin{tabular}{|c|c|}
\hline Diagnoses & Total, n (\%) \\
\hline All & $30,386(100)$ \\
\hline Acute gastroenteritis, all & $11,544(38.0)$ \\
\hline Respiratory tract infections, all & $10,475(34.5)$ \\
\hline \multicolumn{2}{|l|}{ Upper respiratory tract infections } \\
\hline Acute upper respiratory tract infection & 4755 \\
\hline Acute tonsillitis & 1003 \\
\hline Acute sinusitis & 928 \\
\hline \multicolumn{2}{|l|}{ Lower respiratory tract infections } \\
\hline Acute lower respiratory tract infection & 3165 \\
\hline Pneumonia & 557 \\
\hline Influenza* & 67 \\
\hline Ear infections, all & $3843(12.6)$ \\
\hline Otitis media & 2032 \\
\hline Otitis externa & 1811 \\
\hline Dermatologic infections, all & $1538(5.1)$ \\
\hline Infection of skin or subcutaneous tissue & 1222 \\
\hline Erysipelas or cellulitis & 316 \\
\hline Urogenital infections, all & $1305(4.3)$ \\
\hline Pyelonephritis or urinary tract infection & 1133 \\
\hline Infection of female genital organs & 108 \\
\hline Infection of male genital organs & 64 \\
\hline Eye infections, all & $955(3.1)$ \\
\hline Systemic febrile infections, all & $671(2.2)$ \\
\hline \multicolumn{2}{|l|}{ Viral infections } \\
\hline Unspecified viral infection & 249 \\
\hline Varicella-zoster virus infection ${ }^{\mathrm{b} *}$ & 166 \\
\hline Dengue fever & $84^{\mathrm{c}}$ \\
\hline Other specified viral infection & $56^{\mathrm{d}}$ \\
\hline \multicolumn{2}{|l|}{ Bacterial infections } \\
\hline Unspecified bacterial infection & 85 \\
\hline Sepsis & 12 \\
\hline Specified bacterial infection & $11^{\mathrm{e}}$ \\
\hline \multicolumn{2}{|l|}{ Parasite infections } \\
\hline Malaria & $8^{\mathrm{f}}$ \\
\hline Other Infections, all & $55(0.2)$ \\
\hline Intestinal parasites or ectoparasites & 40 \\
\hline Bone or joint infections & 8 \\
\hline Sexually transmitted diseases & $6^{g}$ \\
\hline
\end{tabular}

*Vaccine-preventable disease $(\mathrm{n}=240)$.

a A case was defined as a Finnish traveller abroad with one episode of illness, handled by SOS International during 2010-2012. Anyone with several separate episodes was counted more than once.

b Varicella* 118 , herpes zoster* 48

c In southeast Asia 82, in the Americas 2.

d Hand, foot and mouth disease or herpangina 18, mononucleosis 17, viral meningitis or encephalitis 12 , chikungunya 1 , exanthema subitum 1 , generalized herpes simplex virus infection 1 , hemorrhagic fever with renal syndrome 1 , hepatitis $A^{*} 1$, hepatitis $B^{*} 1$, hepatitis $C 1$, measles* 1 , mumps* 1 .

e Typhoid fever* 3 , borreliosis 2 , scarlatina 2, streptococcal infection 2, bacterial meningitis 1 , pulmonary tuberculosis 1 .

${ }^{\mathrm{f}}$ In Africa 7, in Asia 1.

$\mathrm{g}$ HIV infection 1.

visiting different geographic areas. The figures are considered to represent the most serious cases, i.e. the ones to which pre-travel advice should focus. Acute gastroenteritis (travellers' diarrhoea, TD) and RTI were nearly equally common during travel, while systemic febrile infections proved relatively rare. VPDs were still found, a point to be considered in pre-travel counseling.

\subsection{Incidence of infections}

Incidence of infections proved low in eastern and western Europe and the Americas, and high in Africa, Asia plus Oceania and, somewhat unexpectedly, high also in southern Europe plus the eastern Mediterranean. Earlier, we showed a similar pattern in figures for overall incidence of illness and injury [3], a consequence of the fact that infections represented $60 \%$ of all health problems. Differences between health care services may influence the figures within Europe: in countries with large numbers of tourists in 
Table 4

Proportions of outpatient and inpatient $\operatorname{cases}^{\mathrm{a}}$ by diagnosis category among travellers abroad, 2010-2012.

\begin{tabular}{lllll}
\hline Diagnose category & $\begin{array}{l}\text { Total } \\
\mathrm{n}(\%)\end{array}$ & $\begin{array}{l}\text { Outpatient } \\
\text { cases } \\
\mathrm{n}(\%)\end{array}$ & $\begin{array}{l}\text { Inpatient } \\
\text { cases } \\
\mathrm{n}(\%)\end{array}$ & $\mathrm{p}$ \\
\hline Acute gastroenteritis & $11,5444(100)$ & $8860(76.7)$ & $2684(23.3)$ & $<0.05$ \\
Respiratory tract infections & $10,475(100)$ & $9735(92.9)$ & $740(7.1)$ & $<0.05$ \\
Ear infections & $3843(100)$ & $3726(97.0)$ & $117(3.0)$ & $<0.05$ \\
Dermatologic infections & $1538(100)$ & $1362(88.6)$ & $176(11.4)$ & $<0.05$ \\
Urogenital infections & $1305(100)$ & $1191(91.3)$ & $114(8.7)$ & $<0.05$ \\
Eye infections & $955(100)$ & $955(100.0)$ & 0 & $<0.05$ \\
Systemic febrile infections & $671(100)$ & $450(67.1)$ & $221(32.9)$ & $<0.05$ \\
Other infections & $55(100)$ & $46(83.6)$ & $9(16.4)$ & 0.513 \\
All & $30,386(100)$ & $26,325(86.6)$ & $4062(13.4)$ & \\
\hline
\end{tabular}

${ }^{a}$ A case was defined as a Finnish traveller abroad with one episode of illness, handled by SOS International during 2010-2012. Anyone with several separate episodes was counted more than once.

southern Europe, private clinics directly contacting assistance organizations have evolved, whereas for countries with fewer private hospitals, the proportion of cases reported to SOS may remain smaller [3]. It seems, however, that this would only partly explain the difference, since infection incidence in southern Europe plus the eastern Mediterranean proved substantially higher than in eastern plus western Europe. The highest incidence was for RTI, in contrast to Africa and Asia, where TD ranked first. Although a low risk for TD has been reported for southern Europe [7], we found a significantly higher incidence in southern Europe plus the eastern Mediterranean than in eastern and western Europe or the Americas. Warmer climate and water exposure may readily explain the higher incidence in dermatological, eye, and ear infections in southern Europe plus the eastern Mediterranean, as compared to eastern and western Europe. Interestingly, the incidence of systemic febrile infections proved low in all regions alike.

A short incubation period explains in part the high incidence of TD and RTI during travel. It should, however, be pointed out that TD usually is a spontaneously resolving disease, and mild RTI does not always require health care. Thus, the incidence of these infections, although high in our study, still represents an underestimation of their total burden among travellers.

\subsection{Proportional morbidity}

The most common infection type during travel was TD (38\%), consistent with findings on illness abroad [2,17-20] and after travellers' return $[2,10,13,14]$. RTIs proved, however, nearly as common (35\%). Studies covering also milder diseases have reported somewhat lower figures: in prospective studies, the rate of RTIs during travel has ranged from 3 to 26\% [2,17-20,27]. Sentinel surveillance centres have reported figures between $8 \%$ and $21 \%$ after travel $[10,13,14]$. In our study, TD cases were hospitalized more often than were RTI cases. Duration of hospitalization for TD was short, readily explained both by spontaneous recovery and quick improvement after effective rehydration.

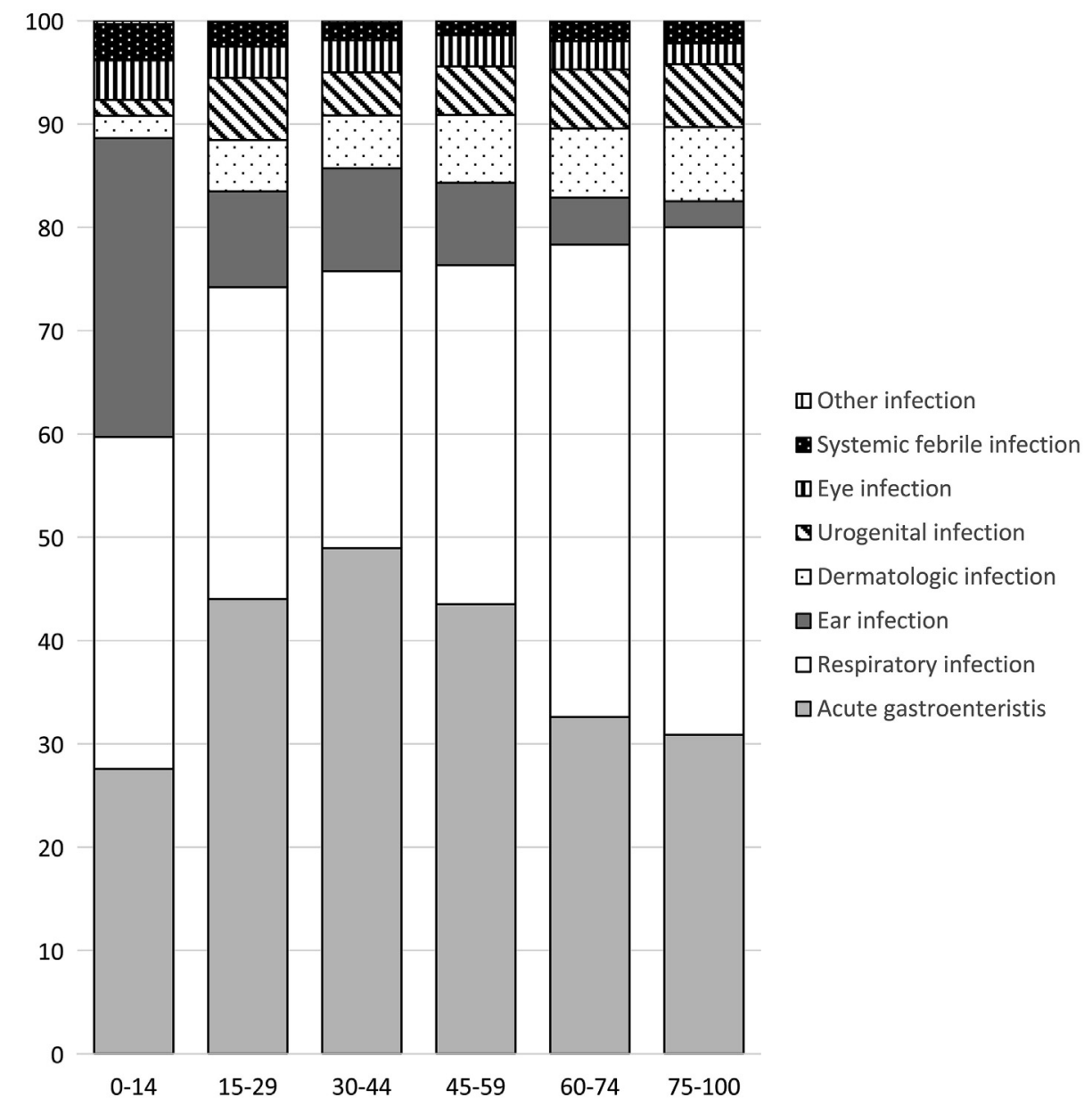

Fig. 2. Percentages of diagnosis categories in various age groups among cases ${ }^{\mathrm{a}}$ abroad with infection diagnoses.

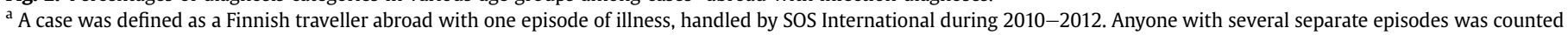
more than once. 
Table 5

Proportions of diagnosis categories by gender of infection cases ${ }^{\mathrm{a}}$ among travelers abroad, 2010-2012.

\begin{tabular}{lllll}
\hline Diagnosis category & $\begin{array}{l}\text { Total } \\
\mathrm{n}\end{array}$ & $\begin{array}{l}\text { Women } \\
\mathrm{n}(\%)\end{array}$ & $\begin{array}{l}\text { Men } \\
\mathrm{n}(\%)\end{array}$ & $\mathrm{p}$ \\
\hline Acute gastroenteritis & 11,544 & $6264(37.0)$ & $5280(39.2)$ & $<0.05$ \\
Respiratory tract infections & 10,475 & $6057(35.8)$ & $4418(32.8)$ & $<0.05$ \\
Ear infections & 3843 & $1714(10.1)$ & $2129(15.8)$ & $<0.05$ \\
Dermatologic infections & 1538 & $837(4.9)$ & $701(5.2)$ & 0.287 \\
Urogenital infections & 1305 & $1080(6.4)$ & $225(1.7)$ & $<0.05$ \\
Eye infections & 955 & $601(3.5)$ & $354(2.6)$ & $<0.05$ \\
Systemic febrile infections & 671 & $354(2.1)$ & $317(2.4)$ & 0.116 \\
Other infections & 55 & $28(0.2)$ & $27(0.2)$ & 0.471 \\
All & 30,386 & $16,935(100)$ & $13,451(100)$ & \\
\hline
\end{tabular}

${ }^{a}$ A case was defined as a Finnish traveler abroad with one episode of illness or injury, handled by SOS International during 2010-2012. Anyone with several separate episodes was counted more than once.

\section{Table 6}

Diagnosis categories by age groups of those who had their flight rescheduled, 2010-2012.

\begin{tabular}{|c|c|c|c|c|c|}
\hline \multirow[t]{2}{*}{ Diagnosis category } & \multirow{2}{*}{$\begin{array}{l}\text { All } \\
\mathrm{n}(\%)\end{array}$} & \multicolumn{4}{|l|}{ Age group } \\
\hline & & $\begin{array}{l}0-14 \mathrm{y} \\
\mathrm{n}(\%)\end{array}$ & $\begin{array}{l}15-19 y \\
n(\%)\end{array}$ & $\begin{array}{l}30-59 y \\
n(\%)\end{array}$ & $\begin{array}{l}60-100 y \\
n(\%)\end{array}$ \\
\hline Acute gastroenteritis & $221(43.4)$ & $57(35.8)$ & $47(58.9)$ & $90(48.4)$ & $27(32.1)$ \\
\hline $\begin{array}{l}\text { Acute respiratory } \\
\text { infections }\end{array}$ & $90(17.7)$ & $13(8.2)$ & $10(12.5)$ & $31(16.7)$ & $36(42.9)$ \\
\hline Ear infections & $75(14.8)^{\mathrm{a}}$ & $40(25.2)$ & $11(13.8)$ & $24(12.9)$ & 0 \\
\hline $\begin{array}{l}\text { Dermatologic } \\
\text { infections }\end{array}$ & $27(5.3)$ & 0 & $2(2.5)$ & $12(6.5)$ & $13(15.5)$ \\
\hline Urogenital infections & $7(1.4)$ & 0 & $2(2.5)$ & $3(1.6)$ & $2(2.4)$ \\
\hline Eye infections & 0 & 0 & 0 & 0 & 0 \\
\hline $\begin{array}{l}\text { Systemic febrile } \\
\text { infections }\end{array}$ & $86(16.9)$ & $49(30.8)^{\mathrm{b}}$ & $8(10.0)^{c}$ & $26(13.9)^{\mathrm{d}}$ & $3(3.6)$ \\
\hline Other infections & $3(0.6)$ & 0 & 0 & 0 & $3(3.6)$ \\
\hline All & $509(100)$ & $159(100)$ & $80(100)$ & $186(100)$ & $84(100)$ \\
\hline
\end{tabular}

Ear infections were the third largest infection group, consistent with the high frequency of these infections in general, especially in children, and thus also during travel. Some activities during travel, such as those related to water recreation during holidays, may serve as predisposing factors and partly explain the high frequency of external otitis. Otitis media, by contrast, may occur anywhere but is often associated with acute respiratory infections, which we found to be frequent during travel. Patients with acute otitis media or acute sinusitis should not fly until pressure in the middle ear or sinuses has resolved $[28,29]$. Of those children having missed their return flight due to infection, $25 \%$ had an ear infection. Of course, in paediatric cases, an adult has to remain behind until the child is fit to fly.

\subsubsection{Systemic febrile infections}

The low incidence of systemic febrile infections in the present study is consistent with other findings on health problems during travel $[2,22]$, yet contrasts with the substantially higher figures in sentinel surveillance studies mostly detecting post-travel problems in specialized centres $[5,10,13-15]$. While sentinel studies found malaria as the most frequent cause of systemic febrile illness $[5,6,10,13-15]$, our data showed malaria in only 8 cases $(1.2 \%)$. The proportion of dengue ( 84 cases; $12.5 \%$ ), by contrast, was similar to that for febrile returned travellers (6-13\%) [5,6,10]. The higher proportion of dengue than malaria cases during travel may relate to its shorter incubation period. Indeed, diseases with a short incubation period may manifest even during a short trip, while those with longer incubation time may manifest after return and thus be better presented in post-travel studies. Interestingly, during the period of the present study, 190 post-travel malaria and 85 dengue cases were reported in our nationwide surveillance system [30].

\subsubsection{Vaccine-preventable diseases}

The proportionate morbidity of VPDs proved relatively low (0.8\%), a finding consistent with post-travel studies of surveillance centres $(0.9-2.3 \%)[9,10,14]$. This probably reflects partly the actual rarity of the exposure and partly the fairly good vaccine coverage among Finnish travellers.

In contrast to studies reporting influenza as the most common VPD among travellers [31,32], in our data, varicella ranked first (49\%), and influenza only second (27\%), followed by herpes zoster (20\%). Varicella-zoster virus infections thus comprised a total of $69 \%$ of VPDs.

Varicella vaccination is included in the childhood vaccination program at national level in only 6 of the 28 European Union countries [33]. The Finnish national vaccination board has recommended adding it to our vaccination program, but this recommendation has yet to be implemented. As the incubation period of varicella is 10-21 days, the infection may have already been contracted before the trip. Developing symptoms of varicella abroad has, however, important practical consequences for the return trip. During the contagious stage of the disease, a patient with varicella has to be isolated and is not allowed fly on commercial aircraft $[28,29]$. According to aeromedical guidelines, the patient can fly ten days after the onset of the rash if the crusts are dry and include no fresh vesicles [28]. Of the varicella cases, $86 \%$ were children under 15 years of age, and $47 \%$ missed their return flight. If the child is very young, because of the isolation, both parents also often have to remain behind. Families with multiple children may have to postpone the return trip of the whole family for a considerable time. Our results lead us to urge that varicella vaccine should be recommended before travel for all immunocompetent children and adults who do not have a history of varicella infection or previous vaccination or are uncertain of such history.

As for herpes zoster, a vaccine is available in many countries. While not traditionally listed as a travellers' vaccine, these data suggest that it could be considered for preventing varicella-zoster virus reactivation during travel, especially in the elderly.

The situation for influenza is clear: annual vaccination against seasonal influenza should be recommended to all travellers alike. The fact that TD remains the most common infection in travellers reminds us of the urgent need for vaccines against TD pathogens. Likewise, the high proportion of RTIs demonstrates the lack of vaccines against the most common respiratory pathogens.

\subsubsection{Sex and age}

The proportion of inpatients was higher among men than women, which accords with the greater proportion of TD cases among men. In older age groups, the proportion of RTIs was higher, but that of TD was lower than in the other groups. Both of these findings actually demonstrate the elementary problem in presenting proportionate morbidity: the percentages represent numbers in relation to one another, not the actual incidence [24]. Based on these data, to draw a conclusion as to whether the decrease in TD proportion with advancing age reflects only an increase in the proportion of RTIs or vice versa, appears impossible. In other studies, the risk for TD has proved highest in infants, toddlers, and young adults [34-36]. 


\subsubsection{Repatriation and deaths}

As causes of death in travellers, infections have been reported to be uncommon, as also shown here. Lunetta [37] analysed the causes of death of Finnish travellers abroad during 1969-2007 finding that infections covered only $1.3 \%$. Infections did not often cause changes in travel plans either, which in part reflects the benign course of the most common disease, TD, usually resolving spontaneously within a few days $[38,39]$.

\subsection{Limitations and strengths}

A few limitations of this study deserve discussion. The paediatric populations could not be included in the incidence calculations because the denominator data of OSF did not include children and, therefore, this group could only be included in figures describing proportional morbidity.

The SOS database included no information on duration of and reason for travel, or on itineraries of individual cases, preventing any evaluation of these factors. Our data do not cover all illnesses during travel. Firstly, the data lacked information on those ill travellers who needed health care services but made no contact with any insurance company or assistance organization while abroad (either making a claim later or not using their insurance). Nor did the data cover those without travel insurance. Secondly, our data do not cover the large group of travellers with mild symptoms who did not use health care services abroad. Our recent prospective study showed only $13 \%$ of travellers with health problems as contacting healthcare providers [27]. Thirdly, as the study material only covered infections during travel, it does not include those infections acquired abroad but only becoming symptomatic after the individual's return. These include especially diseases with a long incubation period.

One of the strengths of the study is that the diagnoses were not reported by travellers themselves after the trip but came directly from clinicians treating the patient abroad. The original medical reports were not available for the study, and thus we did not have information on how the diagnoses were confirmed. Other strengths include the exceptionally large size of the study population $(30,086$ cases) and the fact that it covers $95 \%$ of all Finnish cases abroad handled by assistance organizations.

\section{Conclusions}

While our study does not cover the mildest cases, our data represent quite comprehensively travellers' most serious infections, those upon which pre-travel advice should especially focus. Incidence of travellers' infections proved higher in southern than in eastern and western Europe. TD and RTI proved nearly equally common; the study further emphasizes the need for vaccines against both. Systemic febrile infections proved relatively rare. Among infections targeted by currently available vaccines, the most common proved to be varicella, with influenza ranking second. Indeed, a history of varicella infection or vaccination should be confirmed for all travelling children and adults, and seasonal influenza vaccination should be recommended annually to all travellers.

\section{Funding sources}

This research did not receive any specific grant from funding agencies in the public, commercial, or not-for-profit sectors.

\section{Authors' contributions}

Study concept and design: HS, AK; acquisition of data HS, MF; analysis and interpretation of data $\mathrm{HS}, \mathrm{PK}, \mathrm{AK}$; statistical analysis HS, PK; drafting of the manuscript HS, AK; critical comments on the manuscript PK, MF; final approval of the version published HS, PK, MF, AK.

\section{Conflict of interest}

The authors state they have no conflicts of interest to declare.

\section{Acknowledgments}

We thank Jukka Ollgren (the National Institute for Health and Welfare, Helsinki, Finland) for advice in statistical analysis.

\section{Appendix A. Supplementary data}

Supplementary data related to this article can be found at http:// dx.doi.org/10.1016/j.tmaid.2016.10.007.

\section{References}

[1] UNWTO world tourism organization. UNWTO tourism highlights. edition 2015.. http://mkt.unwto.org/en/publication/unwto-tourism-highlights-2015edition. 2015 [accessed 01.12.15].

[2] Hill DR. Health problems in a large cohort of Americans traveling to developing countries. J Travel Med 2000;7:259-66.

[3] Siikamäki H, Kivelä P, Fotopoulos M, Ollgren J, Kantele A. Illness and injury of travellers abroad: Finnish nationwide data from 2010 to 2012, with incidences in various regions of the world. Euro Surveill 2015;20:15-26.

[4] Leder K, Sundararajan V, Weld L, Pandey P, Brown G, Torresi J, et al. Respiratory tract infections in travelers: a review of the GeoSentinel surveillance network. Clin Infect Dis 2003;36:399-406.

[5] Freedman DO, Weld LH, Kozarsky PE, Fisk T, Robins R, von Sonnenburg F, et al. Spectrum of disease and relation to place of exposure among ill returned travelers. N Engl J Med 2006;354:119-30.

[6] Wilson ME, Weld LH, Boggild A, et al. Fever in returned travelers: results from the GeoSentinel surveillance network. Clin Infect Dis 2007:44:1560-8.

[7] Greenwood Z, Black J, Weld L, O'Brien D, Leder K, Von Sonnenburg F, et al. Gastrointestinal infection among international travelers globally. J Travel Med 2008:15:221-8.

[8] Gautret P, Schlagenhauf P, Gaudart J, Castelli F, Brouqui P, von Sonnenburg F, et al. Multicenter EuroTravNet/GeoSentinel study of travel-related infectious diseases in Europe. Emerg Infect Dis 2009;15:1783-90.

[9] Boggild AK, Castelli F, Gautret P, Torresi J, von Sonnenburg F, Barnett ED, et al. Vaccine preventable diseases in returned international travelers: results from the GeoSentinel surveillance network. Vaccine 2010;28:7389-95.

[10] Field V, Gautret P, Schlagenhauf P, Burchard GD, Caumes E, Jensenius M, et al. Travel and migration associated infectious diseases morbidity in Europe, 2008. BMC Infect Dis 2010;10:330.

[11] Schlagenhauf P, Chen LH, Wilson ME, Freedman DO, Tcheng D, Schwartz E, et al. Sex and gender differences in travel-associated disease. Clin Infect Dis 2010;50:826-32.

[12] Gautret P, Gaudart J, Leder K, Schwartz E, Castelli F, Lim PL, et al. Travelassociated illness in older adults (>60 y). J Travel Med 2012:19:169-77.

[13] Leder K, Torresi J, Libman MD, Cramer JP, Castelli F, Schlagenhauf P, et al. GeoSentinel surveillance of illness in returned travelers, 2007-2011. Ann Intern Med 2013;158:456-68.

[14] Warne B, Weld LH, Cramer JP, Field VK, Grobusch MP, Caumes E, et al. Travelrelated infection in European travelers, EuroTravNet 2011. J Travel Med 2014;21:248-54.

[15] Schlagenhauf P, Weld L, Goorhuis A, Gautret P, Weber R, von Sonnenburg F, et al. Travel-associated infection presenting in Europe (2008-12): an analysis of EuroTravNet longitudinal, surveillance data, and evaluation of the effect of the pre-travel consultation. Lancet Infect Dis 2015;15:55-64.

[16] Liese B, Mundt KA, Dell LD, Nagy L, Demure B. Medical insurance claims associated with international business travel. Occup Environ Med 1997;54: 499-503.

[17] Evans MR, Shickle D, Morgan MZ. Travel illness in British package holiday tourists: prospective cohort study. J Infect 2001;43:140-7.

[18] Winer L, Alkan M. Incidence and precipitating factors of morbidity among Israeli travelers abroad. J Travel Med 2002;9:227-32.

[19] Rack J, Wichmann O, Kamara B, Gunther M, Cramer J, Schonfeld C, et al. Risk and spectrum of diseases in travelers to popular tourist destinations. J Travel Med 2005;12:248-53.

[20] Fleck S, Jager H, Zeeb H. Travel and health status: a survey follow-up study. Eur J Public Health 2006;16:96-100.

[21] Somer Kniestedt RA, Steffen R. Travel health insurance: indicator of serious travel health risks. J Travel Med 2003;10:185-8. 
[22] Leggat PA, Griffiths R, Leggat FW. Emergency assistance provided abroad to insured travellers from Australia. Travel Med Infect Dis 2005;3:9-17.

[23] Lerdal A, Harding T, Kjolstad S. Illness and injury presenting to a Norwegian travel insurance company's helpline. Travel Med Infect Dis 2007;5:165-70.

[24] Leder K, Wilson ME, Freedman DO, Torresi J. A comparative analysis of methodological approaches used for estimating risk in travel medicine. J Travel Med 2008;15:263-72.

[25] Official Statistics of Finland (OSF). Finnish travel. 2014. http://www.stat.fi/til/ smat/index en.html. accessed 26.02.14

[26] World Health Organization (WHO). International statistical classification of diseases and related health problems $10^{\text {th }}$ revision. 2014. http://www.who. int/classifications/icd/en/. accessed 26.02.14.

[27] Vilkman K, Pakkanen SH, Lääveri T, Siikamäki H, Kantele A. Travelers' health problems and behavior: prospective study with post-travel follow-up. BMC Infect Dis 2016;16:328.

[28] The International Air Transport Association (IATA). IATA medical manual. 2016. http://www.iata.org/publications/Pages/medical-manual.aspx. accessed 21.08.16.

[29] Danish aeronautical medical association and SOS international. In: Klokker M Taudorf U, editors. Air travel and transportation of patients; 2016. http:// aeromedicalguidelines.com/forord-gb.html. accessed 21.08.16.

[30] National Institute for Health and Welfare. Infectious diseases in Finland. 2014. http://www.thl.fi/en_US/web/infektiotaudit-en. accessed 26.02.2014.

[31] Mutsch M, Tavernini M, Marx A, Gregory V, Lin YP, Hay AJ, et al. Influenza virus infection in travelers to tropical and subtropical countries. Clin Infect Dis 2005;40:1282-7.

[32] Askling HH, Lesko B, Vene S, Berndtson A, Bjorkman P, Blackberg J, et al Serologic analysis of returned travelers with fever, Sweden. Emerg Infect Dis 2009;15:1805-8.

[33] European Centre for Disease Prevention and Control. Varicella vaccination in the European union. 2015. www.ecdc.europa.eu/en/publications/guidance/ Pages/index.asp. accessed 01.01.15.

34] Hoge CW, Shlim DR, Echeverria P, Rajah R, Herrmann JE, Cross JH. Epidemiology of diarrhea among expatriate residents living in a highly endemic environment. JAMA 1996;275:533-8.

[35] Steffen R, Tornieporth N, Clemens SA, Chatterjee S, Cavalcanti AM, Collard F, et al. Epidemiology of travelers' diarrhea: details of a global survey. J Travel Med 2004; 11:231-7.

[36] Pitzinger B, Steffen R, Tschopp A. Incidence and clinical features of traveler's diarrhea in infants and children. Pediatr Infect Dis J 1991;10:719-23.

[37] Lunetta P. Injury deaths among Finnish residents travelling abroad. Int J Inj Contr Saf Promot 2010;17:161-8.

[38] Pitzurra R, Steffen R, Tschopp A, Mutsch M. Diarrhoea in a large prospective cohort of European travellers to resource-limited destinations. BMC Infect Dis 2010;10:231.

[39] Belderok SM, van den Hoek A, Kint JA, Schim van der Loeff MF, Sonder GJ. Incidence, risk factors and treatment of diarrhoea among Dutch travellers: reasons not to routinely prescribe antibiotics. BMC Infect Dis 2011;11:295. 